DOI: $10.17805 / z p u .2018 .1 .15$

\title{
Музыкально-стилевые предпочтения российских студентов
}

\author{
Е. Н. ПОЛЯНСКАЯ \\ РОССИЙСКИЙ УНИВЕРСИТЕТ ДРУЖБЫ НАРОДОВ, \\ Н. В. КАРГИНА \\ МОСКОВСКИЙ ГУМАНИТАРНЫЙ УНИВЕРСИТЕТ
}

Статья посвящена изучению музыкальных предпочтений современного российского студенчества - социальной группы, чьи эстетические идеалы и социальная идентичность находятся в стадии активного формирования, в процессе которого музыка играет важную воспитательную, организационную, информационную роль. В статье проанализированы основные направления изучения музыкальных предпочтений личности, а также представлены результаты собственного эмпирического исследования. С целью изучения музыкально-стилевых предпочтений российских студентов использовалась анкета музыкальных предпочтений, разработанная Е. С. Борисовой.

Теоретический анализ литературы показывает, что музыкальные предпочтения становятся частью социальной идентификации, соотносятся с молодежной субкультурой, при этом на них оказывают влияние многие факторы: статус, профессиональная деятельность, образование, личный музыкальный опыт и уровень музыкальной подготовки, пол, возраст, гендер, место жительства, СМИ, мода, семья, референтная группа, привлекательность того или иного эмоционального состояния, вызываемого определенной музыкой, увлечения, темперамент, общий интеллект, порог активности, психотип и др. Результаты эмпирического исследования авторами музыкально-стилевых предпочтений российских студентов (Российского университета дружбы народов, 2016 г.) показали, что наиболее часто студенты слушают музыку к кинофильмам, рэп, хип-хоп, далее по степени убывания предпочтений - рок, клубную музыку, классику, классику в современной обработке и музыку для релаксации, панк, джаз и шансон, реже всего - эстраду, этнику, авангардное направление в классике.

Сделан вывод, что музыкально-стилевые предпочтения российских студентов представлены в первую очередь музыкой, являющейся «молодежной» и модной, широко популяризированной для аудитории молодежи в первую очередь благодаря фильмам, музыкальным каналам телевидения, клубам, Интернету, гаджетам. Несмотря на то что музыка становится сегодня неотъемлемой частью повседневной жизни и признается исследователями как самый популярный досуг молодежи, студенты не столь часто слушают музыку, как ожидалось, мало осведомлены о различных ее направлениях и, скорее, являются пассивными потребителями музыки, прослушивание которой носит функциональный характер.

Ключевые слова: музыкальные предпочтения; музыкальный стиль; музыкальный жанр; музыкальное направление; музыкальные вкусы; музыкальная психология; восприятие музыки; музыка; студенты.

\section{ВВЕАЕНИЕ}

$\mathrm{B}$ современном мире музыка стала одним из самых массовых видов искусства, сопровождением жизни человека с самого рождения. В магазинах, транспорте, на телевидении, в компьютерах, разнообразных игровых средствах, мобильных телефонах - музыка постоянно прямо или опосредованно воздействует на индивида через активное или пассивное восприятие. Отмечается огромное количество музыкальных стилей, направлений, которые сказываются на вкусовых предпочтениях людей разного возраста, гендера и культуры. При этом музыкальная культура несет определенную идеологию, формы поведения, стиль, виды активности, 
ценности. Молодежь - тот социальный слой, для которого музыка стала постоянным спутником, одной из наиболее распространенных форм досуга (Наумова, 2016: Электронный ресурс). Музыка играет воспитательную роль, организационную, информационную, помогает личности существовать в социальной группе. Следовательно, роль музыки высока, поэтому необходимо исследовать музыкальные предпочтения молодежи - той социальной группы, эстетические идеалы и социальная идентичность которой находятся в стадии своего активного формирования.

За рубежом научный интерес к исследованию популярной музыки у молодежи отмечается с 20-50 годов XX в. и проявляется в работах М. Абраме (1965); Е. Брауна (1945); Ф. Стюарта (1924); У. Хенди (1958). Музыкальные предпочтения начинают соотносить с различной стратой, субкультурой, социальной идентификацией (Горюнова, 2004; Куликов, 2004). Выделены многие объективные и субъективные факторы, влияющие на музыкальные предпочтения. К объективным факторам относятся пол, возраст, гендер, образование, место жительства, статус, профессиональная деятельность, СМИ, референтная группа, семья, наличие музыкального образования; к субъективным - увлечения, личный музыкальный опыт (занятие музыкой или прослушивание музыкальных произведений), интерес к тому или иному музыкальному произведению, темперамент, общий интеллект, психотип и др. (Нуждина, 2011; Мальцева, 2013; Киселева, 2017; Пантелеев, 2012). Неоднократно отмечались различия в музыкальных предпочтениях у лиц с наличием или отсутствием музыкального образования (Асатрян, 2013; Мальцева, 2013; Нуждина, 2011; Полянская, Беляева, 2016). Аица без музыкального образования предпочитают жанры неакадемической, «легкой» музыки, которая выступает как фон для повседневных дел, средство развлечения, расслабления и отдыха, эмоциональной разрядки (Мальцева, 2013; Нуждина, 2011). Музыка может использоваться для того, чтобы отгородиться от окружающих. Молодежь нередко слушает то, что модно в текущем сезоне (Мальцева, 2013), оценивает музыку по критерию «шлягерности», разрекламированности, внешней яркости. При этом студенты с музыкальным образованием более независимы от моды на музыку (Асатрян, 2013), их музыкальные предпочтения более широки и разнообразны, они чаще слушают музыку, чем студенты без музыкального образования (Полянская, Беляева, 2016).

\section{ЭМПИРИЧЕСКОЕ ИССАЕАОВАНИЕ МУЗЫКАИЬНЫХ ПРЕАПОЧТЕНИЙ РОССИЙСКИХ СТУАЕНТОВ}

Нами было проведено исследование (в апреле - июле 2016 г.) с целью изучения музыкально-стилевых предпочтений российских студентов. Выборку составили 30 российских студентов в возрасте 20-23 лет, обучающиеся в Российском университете дружбы народов. Использовалась анкета музыкально-стилевых предпочтений учащейся молодежи с разным уровнем музыкального образования, разработанная Е. С. Борисовой, включающая 17 музыкальных стилей и направлений (Борисова, 2009), а также свободный пункт, куда по желанию можно дописать отсутствующее музыкальное направление.

Студентам предлагалось определить в баллах, насколько часто они предпочитают слушать то или иное направление или стиль музыки (1 - никогда, 2 - очень 
редко, 3 - иногда, 4 - часто, 5 - очень часто). Результаты исследования отражены в таблице.

МУЗЫКААЬНО-СТИАЕВЫЕ ПРЕАПОЧТЕНИЯ РОССИЙСКИХ СТУАЕНТОВ MUSICAL STYLE PREFERENCES OF RUSSIAN STUDENTS

\begin{tabular}{|l|c|}
\hline \multicolumn{1}{|c|}{ Музькальное направление } & $\begin{array}{c}\text { Cредние значения частотьи выборов } \\
\text { музыкальных направлений и стилей, } \\
\text { в баллах }\end{array}$ \\
\hline Классика & 2,5 \\
Классика в современной обработке & 2,4 \\
Этника & 1,5 \\
Ажаз & 2,2 \\
Бардовская песня & 2 \\
Эстрада & 1,8 \\
Рок & 3,2 \\
Панк & 2,4 \\
Рэп & 3,6 \\
Хип-хоп & 3,5 \\
Аатино & 2 \\
Шансон & 2,2 \\
Ретро & 2,1 \\
Авангардное направление в классике & 1,3 \\
Музыка из кинофильмов & 3,7 \\
Клубная музыка & 3 \\
Музыка для релаксации & 2,4 \\
\hline
\end{tabular}

Результаты ранжирования выборов студентов по степени убывания оказались таковы: первое место по частоте предпочтений прослушивания занимает музыка к кинофильмам $(3,7)$, второе - рэп $(3,6)$, третье место - хип-хоп $(3,5)$, далее: рок $(3,2)$, клубная музыка $(3)$, классика $(2,5)$, классика в современной обработке и музыка для релаксации, панк $(2,4)$, джаз и шансон $(2,2)$, эстрада $(1,8)$, этника $(1,5)$, авангардное направление в классике $(1,3)$.

Музыка из кинофильмов высоко оценивается российскими студентами, - видимо, они часто смотрят фильмы, слушают рингтоны и различные семплы к фильмам.

Рэп пропагандируется в России. Он стал модной молодежной музыкой. Существует большое количество подвидов данного жанра, рассчитанных на разные социальные слои молодежи: «золотой» молодежи мегаполисов, интеллектуалов, «простых пацанов» (в последнем случае рэп сближается с традицией русского шансона). Анализ научных работ, обсуждений в Интернете, в которых делается попытка выявить причины популярности рэпа и хип-хопа в России (Фролова, 2015 и др.), позволяет говорить о том, что в зависимости от направления эта музыка во многом 
совпадает с культурой рока, бардовской песни или является развлекательной легкой музыкой, отвечая разнообразным потребностям молодежи.

Жанр «хип-хоп» (bip - ура, bор - прыжок) также относится к молодежной, модной музыке. Хип-хоп представляет собой музыку и субкультуру афроамериканского и латиноамериканского происхождения (соответствующих кварталов в США, маргинальных групп), которая сначала была андеграундом с характерным бунтарством, нередко эпатажем, отказом от общепринятых ценностей, норм, социальных традиций, языковых ограничений. Затем эта музыка обрела популярность во многом благодаря музыкальному телевизионному каналу MTV и определенным радиостанциям, став жанром массовой культуры, коммерчески прибыльным течением в популярной музыке. В хип-хопе представлены стили от достаточно легких (поп-рэп) до агрессивных (хардкор-рэп, хорроркор); содержание песен варьируется от легкого и непринужденного (например, воспоминаний о «старых добрых временах») до поднятия социальных проблем, отвечая возрастным особенностям и потребностям различных слоев молодежи.

Рок также оценивается высоко в группе студентов, что обусловлено возрастными особенностями выборки. Рок-музыка, с одной стороны, обладает большой захватывающей энергией, имеет много разнообразных направлений, отвечает потребностям в свободе от устоявшихся норм и общественных стереотипов, с другой стороны, она является одним из инструментов шоу-бизнеса, индустрии развлечений.

После молодежных жанров классика - направление, которое студенты слушают время от времени. Классическая музыка требует специального прослушивания, сосредоточенности (Петрушин, 2008). Анализ исследований позволяет предположить, что ее предпочтение зависит от уровня музыкальной подготовки, популяризации в обществе (Мальцева, 2013; Полянская, Беляева, 2016; Ван, Полянская, 2016), урбанизированности (Вершинин, Холодов, Богатырева, 2016).

Классика в современной обработке менее популярна, хотя здесь классическая музыка приобретает более современное звучание благодаря использованию электронных инструментов, при этом берутся лучшие образцы классики. Такую музыку тоже нередко можно услышать на радиостанциях или при музыкальном сопровождении видеоряда, но не так часто, как более популярные направления. То же самое можно сказать о музыке для релаксации, которая заключается в музыкальности, мелодичности, является чаще инструментальной.

Панк-музыка, получившая в России активное развитие в 1980-1990 гг., в эпоху революционных преобразований в стране, у современных студентов 2000-х годов теряет актуальность. Эта музыка отличается нарочитой задиристостью и драйвом, простым аккомпанементом, развязной и зачастую агрессивной манерой пения, нигилистичностью текстов, содержащих критику современных социальных проблем, исполнители часто имеют эпатажный имидж. Видимо, направление вытеснено рэпом и хип-хопом, отвечающим более широким потребностям.

Ажаз, шансон, латино, этника, бардовская песня, авангардное направление в классике наименее популярны среди студентов. На наш взгляд, это объясняется их «немодностью», слабой популяризацией. Место шансона и бардовской песни занял рэп, музыка для развлечения и отдыха в большей степени представлена другими модными направлениями. 
Ажаз остается элитарной музыкой. Студенты фактически никогда не слушают музыкальный авангард, поскольку он характеризуется экспериментами и известен, пожалуй, только узкому кругу. Это вид современной академической музыки, некоторые элементы эстетики которой являются радикально инновационными. Несмотря на то что студенты, участвующие в опросе, учатся в международно-ориентированном вузе, этническая музыка не стала для них популярной или предпочитаемой. В социокультурном пространстве вуза в основном звучит музыка массовой культуры.

\section{ЗАКАЮЧЕНИЕ}

Теоретический анализ литературы позволяет сделать вывод о том, что музыкальные предпочтения играют роль социальной идентификации, являются частью молодежной субкультуры, связаны со многими объективными и субъективными факторами: полом, возрастом, гендером, местом жительства, образованием, личным музыкальным опытом и уровнем музыкальной подготовки, модой, привлекательностью того или иного эмоционального состояния, вызываемого определенной музыкой, личностными особенностями и др. Эмпирическое исследование музыкально-стилевых предпочтений российских студентов показывает их связь с особенностями молодежной выборки, пропагандируемостью тех или иных жанров, доминирующими формами досуга. Чаще всего студенты слушают музыку к кинофильмам в силу популярности данного вида досуга, часто используют ее в качестве рингтонов в мобильных телефонах. Рок, хип-хоп, клубная музыка являются «молодежными» направлениями, широко популяризированными для этой аудитории, в первую очередь благодаря музыкальным каналам телевидения, клубам, Интернету, гаджетам. Студенты иногда слушают классическую музыку, в том числе в современной обработке; реже - панк-музыку и почти не слушают джаз, латино и другую этнику, шансон, бардовскую песню, авангард в классической музыке. Видимо, выбор классики связан с воспитанием, образованием, музыкальным опытом, а другие направления вытесняются более модными хип-хопом, рэпом, роком с их разнообразием поднаправлений, рассчитанных на разную молодежную аудиторию. Следует отметить, что студенты мало осведомлены о различных направлениях музыки, в своем большинстве являясь пассивными потребителями массовой музыки, прослушивание которой носит функциональный характер.

\section{СПИСОК АИТЕРАТУРЫ}

Асатрян, О. Ф. (2013) Музыкальные предпочтения студентов - будущих учителей музыки // Вестник кафедры ЮНЕСКО «Музыкальное искусство и образование». № 3. С. 42-48.

Борисова, Е. С. (2009) Психологические особенности категориальной организации восприятия музыки учащейся молодежью с разным уровнем музыкального образования : автореф. дис. ... канд. психол. наук. Самара. 24 с.

Ван, Аинь Аи, Полянская, Е. Н. (2016) Особенности музыкально-стилевых предпочтений китайских студентов // Иичность в природе и обществе : науч. тр. молодых ученых (материалы межвузовских психолого-педагогических чтений. Москва, 21 апреля 2016 г.) / сост. и науч. ред. А. В. Иващенко, Н. Б. Карабущенко, Е. Н. Полянская. М. : РУАН. 213 с. С. 17-20.

Вершинин, А., Холодов, Я., Богатырева, Ж. В. (2006) Музыкальные предпочтения студенческой молодежи // Международный студенческий научный вестник. № 5-1. С. 12-15. 
Горюнова, А. О. (2004) Социокультурные аспекты формирования музыкальных предпочтений современной российской молодежи : дис. ... канд. социол. наук. Саратов. 181 с.

Киселева, С.А. (2017) Влияние характеристик личности на музыкальные предпочтения [Электронный ресурс] // Молодой ученый. № 19. C. 276-279. URL: https://moluch.ru/archive/153/ 43353/ (дата обращения: 26.07.2017).

Куликов, Е. М. (2004) Музыкальные предпочтения как дифференцирующий и интегрирующий фактор российской молодежной субкультуры : автореф. дис. ... канд. социол. наук. Ставрополь. 24 с.

Мальцева, Н. В. (2013) Музыкальные предпочтения современной молодежи на примере города Иркутска // Культура. Ауховность. Общество. № 4. С. 147-151.

Наумова, К. В. (2016) Музыкальные предпочтения молодых людей с разными типами личности (на примере студентов факультета социологии ААТГУ) [Электронный ресурс]// Аискурс. № 1(1). C. 219-222. URL: http://journal-discurs.ru/files/arkhiv-zhurnala/1-2016/1-4.Naumova.pdf (дата обращения: 25.07.2017).

Нуждина, А. А. (2011) Музыкальные предпочтения молодых людей с разным профессиональным образованием // Известия Российского государственного педагогического университета им. А. И. Герцена. СПб. : Изд-во Российского гос. педагогического университета им. А. И. Герцена. № 139. С. 73-78.

Пантелеев, А. Ф. (2012) Взаимосвязь музыкальных предпочтений и психологических особенностей слушателей музыки // Известия Саратовского университета. № 2. С. 67-72.

Петрушин, В. И. (2008) Музыкальная психология. М. : Академический Проект. 400 с.

Полянская, Е. Н., Беляева, А. В. (2016) Музыкально-стилевые предпочтения студентов с разным уровнем музыкальной подготовки // Здоровье и образование в XXI веке. Т. 18. № 6. C. $136-141$.

Фролова, Е. В. (2015) Рэп как форма социально-политической рефлексии в современной российской культуре (2009-2013 гг.) М. : Изд. дом Высшей школы экономики. 52 с.

Aата поступления: 26.08.2017 2.

\section{MUSIC STYLE PREFERENCES OF RUSSIAN STUDENTS \\ E. N. Polyanskaya \\ PEOPLES' FRIENDSHIP UNIVERSITY OF RUSSIA, \\ N. V. KARGINA \\ MOSCOW UNIVERSITY FOR THE HUMANITIES}

The article is devoted to the study of the musical preferences of modern Russian students - the social group whose aesthetic ideals and social identity are in a stage of its active formation, in which music plays an important educational, organisational, and informational role. The article analyses the main tendencies in the study of music preferences of the individual and presents the results of an own empirical research. To study Russian students' music style preferences the questionnaire of music preferences created by E. S. Borisova was used.

A theoretical analysis of the literature shows that music preferences are becoming part of social identification, relate to the youth subculture, while they are influenced by many factors: status, professional activity, education, personal musical experience and the level of musical training, sex, age, gender, place of residence, mass media, fashion, family, reference group, the appeal of one or another emotional state caused by a particular genre, hobbies, temperament, overall intelligence, the threshold of activity, psychological type, and others. The results of the authors' empirical study of music style preferences of Russian students (at Peoples' Friendship University of Russia) showed that most frequently students listen to film soundtracks, rap, hip-hop; then by the degree of decreasing preference - rock, club music, classics, classics in modern remakes and music for relaxation, punk, jazz and chanson, least often - pops, ethnics, avant-garde trend in classics. 
The conclusion is that the music style preferences of Russian students are represented primarily by the music widely popularised for young audiences, primarily due to films, music channels, clubs, the Internet, and gadgets, because it is modern and fashionable. Despite the fact that today music is becoming an integral part of everyday life, and is recognised by researchers as the most popular leisure activity among young people, students do not listen to music as often as it was expected, have little awareness of its trends, and are rather passive consumers of music, listening to which has a functional character.

Keywords: music preferences; music style; music genre; music trend; music tastes; music psychology; perception of music; music; students

\section{REFERENCES}

Asatrian, O. F. (2013) Muzykal'nye predpochteniia studentov - budushchikh uchitelei muzyki. Vestnik kafedry IuNESKO "Muzykal' noe iskusstvo i obrazovanie», no. 3, pp. 42-48. (In Russ.).

Borisova, E. S. (2009) Psikbologicheskie osobennosti kategorial' noi organizatsii vospriiatiia muzyki uchashcheisia molodezh' iu s raznym urovnem muzykal' nogo obrazovaniia: Thesis of Dis.... Candidate of Psihology. Samara. 24 p. (In Russ.).

Van, Lin' Li, Polianskaia, E. N. (2016) Osobennosti muzykal'no-stilevykh predpochtenii kitaiskikh studentov. In: Lichnost' $v$ prirode $i$ obshchestve : nauch. tr. molodykb uchenykb (materialy mezbvuzovskikh psikbologo-pedagogicheskikb chtenii. Moskva, 21 aprelia 2016 g.) / Ed. by A. V. Ivashchenko, N. B. Karabushchenko and E. N. Polianskaia. Moscow, RUDN. 213 p. Pp. 17-20. (In Russ.).

Vershinin, A., Kholodov, Ia. and Bogatyreva, Zh. V. (2006) Muzykal'nye predpochteniia studencheskoi molodezhi. Mezhdunarodnyi studencheskii nauchnyi vestnik, no. 5-1, pp. 12-15. (In Russ.).

Goriunova, L. O. (2004) Sotsiokul'turnye aspekty formirovaniia muzykal'nykb predpocbtenii sovremennoi rossiiskoi molodezhi : Dis. ... Candidate of Sociology. Saratov. 181 p. (In Russ.).

Kiseleva, S. D. (2017) Vliianie kharakteristik lichnosti na muzykal'nye predpochteniia. Molodoi uchenyi, no. 19, pp. 276-279 [online] Available at: https://moluch.ru/archive/153/43353/ (access date 26.07.2017). (In Russ.).

Kulikov, E. M. (2004) Muzykal' nye predpocbteniia kak differentsiruiushchii i integriruiushchii faktor rossiiskoi molodezhnoi subkul' tury: Thesis of Dis.... Candidate of Sociology. Stavropol'. 24 p. (In Russ.).

Mal'tseva, N. V. (2013) Muzykal'nye predpochteniia sovremennoi molodezhi na primere goroda Irkutska. Kul'tura. Dukbovnost'. Obshchestvo, no. 4, pp. 147-151. (In Russ.).

Naumova, K. V. (2016) Muzykal'nye predpochteniia molodykh liudei s raznymi tipami lichnosti (na primere studentov fakul'teta sotsiologii ALTGU). Diskurs, no. 1(1), pp. 219-222 [online] Available at: http://journal-discurs.ru/files/arkhiv-zhurnala/1-2016/1-4.Naumova.pdf (access date: 25.07.2017). (In Russ.).

Nuzhdina, A. A. (2011) Muzykal'nye predpochteniia molodykh liudei s raznym professional'nym obrazovaniem. Izvestiia Rossiiskogo gosudarstvennogo pedagogicheskogo universiteta im. A. I. Gertsena, no. 139, pp. 73-78. (In Russ.).

Panteleev, A. F. (2012) Vzaimosviaz' muzykal'nykh predpochtenii i psikhologicheskikh osobennostei slushatelei muzyki. Izvestiia Saratovskogo universiteta, no. 2, pp. 67-72. (In Russ.).

Petrushin, V. I. (2008) Muzykal'naia psikbologiia. Moscow, Akademicheskii Proekt. 400 p. (In Russ.).

Polianskaia, E. N. and Beliaeva, A. V. (2016) Muzykal'no-stilevye predpochteniia studentov s raznym urovnem muzykal'noi podgotovki. Zdorov'e $i$ obrazovanie $v X X I$ veke, vol. 18, no. 6, pp. 136-141. (In Russ.).

Frolova, E. V. (2015) Rep kak forma sotsial'no-politicheskoi refleksii v sovremennoi rossiiskoi kul'ture (2009-2013 gg.). Moscow, Izd. dom Vysshei shkoly ekonomiki. 52 p. (In Russ.). 
Полянская Екатерина Николаевна - кандидат психологических наук, доцент кафедры психологии и педагогики Российского университета дружбы народов. Адрес: 117198, Россия, г. Москва, ул. Миклухо-Маклая, А. 6. Тел.: +7 (495) 434-37-45. Эл. aдpec: polyanskayae@mail.ru

Каргина Наталья Вячеславовна - кандидат психологических наук, доцент, доцент кафедры общей психологии и истории психологии Московского гуманитарного университета. Адрес: 111395, Россия, г. Москва, ул. Юности, д. 5. Тел.: +7 (499) 374-67-20. Эл. адpec: kanat99@ya.ru

Polyanskaya Ekaterina Nikolayevna, Candidate of Psychology, Associate Professor, Department of Psychology and Pedagogy, Peoples' Friendship University of Russia. Postal address: 6, MiklukhoMaklaya St., Moscow, Russian Federation, 117198. Tel.: +7 (495) 434-37-45. E-mail: polyanskayae@mail.ru

Kargina Nataliya Vyacheslavovna, Candidate of Psychology, Associate Professor, Associate Professor, Department of General Psychology and History of Psychology, Moscow University for the $\mathrm{Hu}-$ manities. Postal address: 5, Yunosti St., Moscow, Russian Federation, 111395. Tel.: +7(499) 374-67-20. E-mail:kanat99@ya.ru 